\title{
Kernos
}

Revue internationale et pluridisciplinaire de religion grecque antique

$17 \mid 2004$

Varia

\section{Hommage à Jean Rudhardt}

\section{Philippe Borgeaud}

Édition électronique
URL : http://journals.openedition.org/kernos/1398

DOI : 10.4000/kernos.1398

ISSN : 2034-7871

\section{Éditeur}

Centre international d'étude de la religion grecque antique

Édition imprimée

Date de publication : 1 janvier 2004

ISSN : 0776-3824

\section{Référence électronique}

Philippe Borgeaud, « Hommage à Jean Rudhardt », Kernos [En ligne], 17 | 2004, mis en ligne le 22 avril 2011, consulté le 01 mai 2019. URL : http://journals.openedition.org/kernos/1398 


\section{Hommage à Jean Rudbardt}

Jean Rudhardt, professeur honoraire de l'Université de Genève, nous a quittés le dimanche 29 juin 2003. Homme de grande culture, d'une intelligence impressionnante, animé de rigueur et de probité, ce maître discret a diffusé, souvent à son insu, son rayonnement bien au-delà de sa chaire. Jean Rudhardt laisse le manuscrit interrompu d'un livre intitulé De la religion. Il travaillait aussi, à nouveau, sur les notions fondamentales de la pensée religieuse grecque, ainsi que sur les Hymmes orphiques. On peut se faire une idée de l'état le plus récent de sa pensée en lisant notamment trois textes publiés peu avant sa disparition: "Considérations sur la notion de sebas ", dans Homère chez Calvin. Mélanges Olivier Reverdin, Genève, Droz, 2000, p. 421434; "Quelques remarques sur la notion d'aidôs», dans Édouard Delruelle, Vinciane Pirenne-Delforge (éds), Kĩnol. De la religion à la philosophie. Mélanges offerts à André Motte, Liège, 2001 (Kemos Supplément no 11), p. 121, et «Les deux mères de Dionysos, Perséphone et Sémélé, dans les Hy'mnes orphiques », Revue de l'bistoire des religions 219 (2002), p. 483-501'.

Né à Genève le 14 janvier 1922, Jean Rudhardt avait eu pour maîtres, au Collège de cette ville, certains des élèves directs de Ferdinand de Saussure. Il fut marqué par cet enseignement. Structuraliste bien avant la lettre, il fit un parcours classique et humaniste, sous la direction notamment de l'helléniste Victor Martin. Avant d'enseigner à son tour le grec, la papyrologie et l'histoire des religions à l'Université de Genève, il fut directeur, pendant sept ans (de 1953 à 1960), du Sanatorium universitaire suisse à Leysin, dont il fit un haut lieu d'échanges intellectuels : cette étape liminale, marquée par l'expérience de la tuberculose, fut celle d'une intense agitation d'idées et de sentiments. Il n'a cessé de l'évoquer.

Helléniste et papyrologue, philosophe aussi (ancien marxiste), mathématicien à ses heures ${ }^{2}$, ce grand savant est surtout connu pour sa thèse sur les rituels sacrificiels et le vocabulaire de la piété grecque, Notions fondamentales de la pensée religieuse et actes constitutifs du culte dans la Grèce classique, parue à Genève, chez Droz, en 1958 et rééditée à Paris, chez Picard, en 1992.

\footnotetext{
1 Une bibliographie complète de Jean Rudhardt est disponible sur le site internet dont l'adresse est la suivante : http://www.unige.ch/lettres/antic/HR/

${ }^{2}$ Cf. «Trois problèmes de géométrie conservés par un papyrus genevois », Museum Helveticum 35 (1978), 233-240 (papyrus repris dans Les papynls de Genève, troisième volume, publié par P. Schubert. Genève, 1996).
} 
Cet ouvrage de référence apparaît comme un monument hors contexte. Il échappe en grande partie aux débats qui lui sont contemporains. Le directeur de cette thèse, Victor Martin, avait publié un compte rendu très fidèle des Griechiscbe Opferbraüche de Karl Meuli'. On connaît le destin des thèses de Meuli, qui devaient avoir (bien après le travail de Rudhardt) une grande influence sur les travaux de Walter Burkert. Jean Rudhardt, lui, reste insensible à cette approche résolument comparatiste. Il la connaît. Il préfère l'ignorer". Il n'appartient, il faut le dire, à aucune école dans sa spécialité. Il n'a reçu l'enseignement direct d'aucun historien des religions et l'on peut dire de son livie sur le sacrifice, construit (à la suggestion de Victor Martin) à partir d'une lecture systématique des orateurs athéniens, qu'il fut écrit quasiment en autodidacte, ce qui explique sa frâtcheur, sa grande originalité et son succès scientifique: il a nourri, surtout en francophonie, deux générations d'étudiants et de chercheurs en religion grecque ancienne.

Jean Rudhardt a redéfini et revitalisé la chaire genevoise d'histoire des religions fondée en 1874 qui fut localisée pour lui, à nouveau, en Faculté des Lettres après un long passage en Théologie. Il en fut le titulaire de 1965 à 1987. Ses réflexions très personnelles et fécondes sur le langage mythiques, sur le thème de l'eau primordiale ${ }^{6}$, sur l'orphisme (en particulier celui des Hymnes orpbiques dont il nous a appris à reconnaître l'importance $)$, le situent dans un courant de pensée proche à la fois de l'inspiration phénoménologique et de la démarche historique et anthropologique la plus respectueuse des textes et des contextes. Pour Rudhardt, l'essentiel, si l'on veut comprendre quelque chose de l'autre, qu'il soit Grec ancien ou simplement contemporain, d'une autre religion ou d'une autre culture, c'est de faire l'effort de comprendre sa langue, de l'écouter dans ses propres modes d'expression, de pénétrer dans son système de pensée et d'expérience humaine. Cet exercice de traduction constitue une véritable ascèse, dont il n'a cessé de nous clonner des exemples, notamment à partir de son enseignement du thème grec ${ }^{8}$.

Ce savoir d'expérience résulte d'une plongée dans la matière, celle des sources, des textes, des documents. Ce n'est pas un savoir emprunté à une quelconque autorité. Mais c'est un savoir qui revendique une autorité. Dans

\footnotetext{
${ }^{3}$ Victor Martin, "L'ethnographie et la préhistoire au service de l'interprétation des classiques ", Archives suisses d'antbropologie générale 13 (1947-1948), p. 56-71.

4 Il ne critiquera explicitement les thèses de Meuli que bien plus tard dans un texte qui, lui, aura une influence certaine sur l'école de Jean-Pierre Vernant: "Les mythes grecs relatifs à l'instauration du sacrifice : les rôles corrélatifs de Prométhée et de son fils Deucalion ", Museum Helvelicum 27 (1970), p. 1-15.

${ }^{5}$ Du mytbe, de la religion grecque et de la compréhension d'autrui, Genève, Dtoz, $1981=$ Revue Européenne des sciences sociales el Cabiers Vilfredo Pareto, Tome XIX, no 58.

"Le thème de l'eau primordiale dans la mythologie grecque, Beme, Francke, 1971.

7 "Quelques réflexions sur les hymnes orphiques", in Orphisme et Orpbée en l'honneur de Jean Rudbardt, textes réunis et édités par Ph. Borgeaud, Droz, Genève, 1991, 263-289.

" "Réflexions philosophiques à l'occasion d'un exercice de traduction ", Cabiers Ferdinand de Saussure, Genève, 1964, p. 55-85 (republié dans Du mythe, de la religion grecque et de la compréhension d'aulmii).
} 
ses cours, dans ses interventions lors de colloques, cela pouvait donner lieu à de remarquables affirmations : les théoriciens du prêt-à-porter, les adeptes des herméneutiques à la mode ont conclu ou simplement affirmé ceci ou cela; "ils ont peut-être raison; sans trop discuter de leurs hypothèses, nous nous poserons des questions d'un autre type ». Quelle questions? Celles que devaient se poser les Grecs eux-mêmes, tels que Jean Rudhardt, devenu Grec, les avait entendues. D'autres Grecs, les collègues sérieux de Rudhardt, pouvaient éventuellement poser d'autres questions...

Une telle conviction suppose l'écoute, intégrale, de l'autre. Et même plus que cela : elle suppose que l'on devienne autre. La méthode, au fond, correspond à la démarche religieuse des Grecs eux-mêmes, telle que Jean Rudhardt l'a si bien reconstituée : les Grecs n'ont pas de Bible, pas de livres rituels, pas de clergé, pas de dogme, pas de charpente théorique. Mais ils ont le plus grand respect des vieilles expériences collectives, celles qui furent accumulées par la tradition et l'inspiration. Ces expériences, chaque culture leur donne une expression particulière. Les Grecs savent aussi, ou au moins ils le pressentent, que derrière les styles et les formes infiniment variés et transitoires que revêtent, ici ou là, en des temps divers, les pensées religieuses et les coutumes traditionnelles, il y a un sens, permanent, universel, indicible, caché'.

Jean Rudhardt a participé à la découverte de deux textes papyrologiques importants du christianisme antique conservés à Genève. Il les a édités respectivement avec A. Hurst et $O$. Reverdin, PAPYRUS BODMER XXIX. Vision de Dorothéos. Edité avec une introduction, une traduction et des notes, Genève, Fondation Martin Bodmer, 1984; et avec A. Hurst, PAPYRI BODMER XXX-XXXVII. "Codex des Visions». Poèmes divers. Édités avec une introduction générale, des traductions et des notes, Münich, Saur, 1999.

Son dernier livre publié, Thémis et les Hôrai. Recherches sur les divinités grecques de la justice et de la paix (Genève, Droz, 1999) est une très belle réflexion sur le lien essentiel qui unit, dans la pensée et dans le sentiment religieux des Grecs, les manifestations divines - l'évidence de multiples présences - à ce que nous appellerions des «valeurs » morales. C'est aussi un parcours d'une rare intensité dans cette littérature qu'il pratiquait en Grec et en croyant, et dont il restitue, dans une traduction qui est toujours la sienne, un choix de textes magnifique.

Philippe BORGEAUD

\footnotetext{
" "Les formes transitoires de la pensée et la permanence du sens », Revue de théologie et de philosophie, Lausanne, 1971, p. 13-23 (republić dans Du mythe, de la religion grecque et de la comprébension d'autruit).
} 